\title{
AS DÉBEIS ARTICULAÇÕES COMO REFERÊNCIA DE GESTÃO DOS INSTITUTOS FEDERAIS
}

\author{
F. C. M. FERNANDES* \\ Instituto Federal de Educação, Ciência e Tecnologia do Rio Grande de Norte \\ francisco.mariz@ifrn.edu.br \\ Submetido 17/09/2016 - Aceito 15/12/2016 \\ DOI: $10.15628 /$ holos.2016.5093
}

\section{RESUMO}

Simultaneamente burocrática e anárquica, sob tensões de uma estruturação matricial com ancoragem entre centralização e descentralização, a organização educacional Instituto Federal abrange múltiplas dimensões e imagens, demanda articulações fracas para funcionar adequadamente, e estruturalmente, enquadra-se e pode ser igualado, em termos de parâmetros, à configuração de uma Estrutura Divisionalizada (MINTZBERG, 1995). O campo de tensões e de relações de forças que se cria entre a administração central, a gestão multicampi e as comunidades escolares, na maioria do tempo de estabilidade, advinda de consensos e acomodações, oportunizam, também, instabilidades e conflitos. Essa imagem é coerente com a compreensão exposta por Weick (1976) de que em contraste com a imagem predominante de que elementos em organizações são acoplados através de ligações densas e apertadas, na prática, esses elementos são, apenas, fracamente conectados uns aos outros, ou seja, constituem-se em um "sistema debilmente articulado".

PALAVRAS-CHAVE: Acoplamentos Fracos, Anarquia Organizada, Burocracia, Gestão Interdependente, Multicampi.

\section{THE WEAK ARTICULATIONS AS REFERENCE OF MANAGEMENT OF FEDERAL INSTITUTES}

\begin{abstract}
Both bureaucratic and anarchic under tension of a matrix structure with anchoring between centralization and decentralization, educational organization Federal Institute comprises multiple dimensions and images, demands weak articulations to function properly, and structurally fits and can be matched, in terms of parameters, the configuration of a Divisionalized Structure (Mintzberg, 1995). The field of stresses and forces relations created between the central administration, multicampi management and school
\end{abstract}

communities, most of the time stable, arising out consensus and accommodation, nurture, too, instabilities and conflicts. This picture is coherent with the understanding expounded by Weick (1976) that in contrast to the prevailing image that elements in organizations are coupled through dense and tight connections, in practice, these elements are only weakly connected to each other, that is, they are constituted in a "loosely coupled system".

KEYWORDS: Weak Couplings, Organized Anarchy, Bureaucracy, Interdependent Management, Multicampi. 


\section{INTRODUÇÃO}

Estudos de modelos organizacionais historicamente efetivados com base nas ciências da administração avançaram nos Estados Unidos na década de 50 do século XX com a incorporação do ponto de vista teórico-metodológico de outros conhecimentos das ciências sociais, especialmente da sociologia e da psicologia social. Essas investigações e trabalhos receberam a denominação de "New Movement" vinculado ao princípio da construção da "ciência da Administração Educacional" com base em conceitos abrangentes e operacionalmente objetivos no tocante à orientação da ação dos administradores. Na mesma direção, na Europa, entre as décadas de 70 e 80 do referido século passado, foram efetivados diversos estudos de valorização da escola como organização, no campo teórico da administração educacional, que mudaram o quadro conceitual, epistemológico e metodológico da, até então, área disciplinar, elevando-a para paradigmas mais próximos da escola como organização (LIMA, 2011b, p. 160) educativa, favorecendo os processos de investigações sobre direção, administração e procedimentos organizacionais, vivenciados nas instituições de educação.

Essa conjuntura e acontecimentos que resultaram em um novo cenário para a análise da administração educacional são julgados como o início de "novos paradigmas", uma vez que representaram uma reviravolta na abordagem anterior de investigação da área, até então, estritamente vinculada ao âmbito da ciência política, psicologia, economia e sociologia. No entendimento de Costa (1996, p. 23), os "novos paradigmas de que se fala consistem em novas concepções teóricas sobre organização e administração escolar e em novos posicionamentos metodológicos que, rejeitando o 'positivismo vigente nas ciências sociais', afirmam, em alternativa, perspectivas de análise de feição 'interpretativa' e 'crítica'". No contexto, as teorias das organizações abrem espaço para os estudos sociológicos de compreensão crítica dos modelos da escola como organização.

Relativamente aos fundamentos da área da Administração Educacional, sobressaem os relevantes estudos referentes à análise da "Escola como Organização" realizados em Portugal, por Licínio Lima (1992b, p. 6) que destaca o tema Organizações Educativas como "uma proposta de abordagem científica e disciplinar" e chama a atenção para as "vantagens de associar a esta área a perspectiva de uma Sociologia das Organizações Educativas e da Administração Educacional, com vocação teórica e analítica".

Em termos de educação brasileira e latino-americana, à época, apesar do foco desenvolvimentista de administração pública vivenciado no país, foram iniciados alguns estudos na perspectiva sociocultural, apoiados em concepções conceituais e analíticas das ciências sociais aplicadas. Para Sander (2007, p. 49), na educação brasileira, o protagonista mais influente do "pensamento crítico do século XX foi Paulo Freire (1989), que reconstruiu na teoria pedagógica as relações de dominação e os ideais de libertação que a teoria da dependência postulara no âmbito das relações econômicas e políticas internacionais". Ainda, sobre o tema, em um trabalho acerca dos esforços históricos de produção de conhecimentos na área da administração da educação no Brasil, o autor contextualiza que, na década de 60 do século XX, "observa-se na América Latina 
uma crescente utilização das ciências sociais na gestão da educação na linha da tradição teórica da escola contemporânea de administração" (SANDER, 1982, p. 9). Nos dias atuais, investigadores da área da educação têm-se posicionado, criticamente, quanto aos avanços, no século XXI, do pensamento neoliberal na administração das organizações educativas sob o pretexto de modernizar os sistemas e as instituições de ensino com concepções importadas da área da administração empresarial, aproximando-as, assim, do mundo produtivo globalizado.

Este artigo está fundamentado em estudos de investigação de natureza qualitativa realizada no âmbito de tese de doutoramento do autor.

\section{ALGUNS MODELOS E REALIDADES ORGANIZACIONAIS DAS ESCOLAS}

Estudos referentes às características das organizações educacionais levaram Per-Erik Ellström (2007) a definir e propor as faces denominadas: racional, política, de sistema social e anárquica, da escola como organização; associando essas faces a suposições ou concepções vinculadas à realidade das organizações, num arranjo de conceitos de bases descritivas e analíticas. A figura 1 representa o quadro de tipologia dos quatro modelos organizacionais, propostos por Ellström, apresentados sob a ótica matricial que, num dos eixos, considera a tecnologia e processos organizacionais com base nas variáveis "transparentes/claros" ou "ambíguos/não claros"; e, no outro eixo, considera os objetivos e preferências organizacionais com base nas variáveis "claros e compartilhados (consenso)" ou "obscuros e/ou não partilhados (conflito)".

Conforme demonstrado na figura 1, o modelo racional é conceitualmente associado: à verdade, ao pensamento e ao trabalho orientado e, em termos de estruturação organizacional, voltado para tecnologias/procedimentos e objetivos claros, certos e partilhados. Contudo, segundo Lima (2011a, p. 24), a racionalidade "não é exclusiva do modelo racional, assume contornos diferentes e está presente em outros modelos e, por outro lado, a burocracia, em sentido weberiano, constitui o modelo mais racional".

Quadro 1: Tipologia dos quatro modelos organizacionais segundo Per-Erik Ellström. Fonte: Ellström (2007, p. 456).

\begin{tabular}{|l|l|l|l|}
\cline { 3 - 4 } \multicolumn{2}{c|}{} & \multicolumn{2}{c|}{ (a) Objetivos e preferências organizacionais } \\
\cline { 3 - 4 } \multicolumn{2}{c|}{} & \multicolumn{1}{c|}{$\begin{array}{c}\text { Claros e compartilhados } \\
\text { (consenso) }\end{array}$} & $\begin{array}{c}\text { Obscuros e/ou não } \\
\text { partilhados } \\
\text { (conflito) }\end{array}$ \\
\hline $\begin{array}{l}\text { (b) Tecnologia } \\
\text { e Processos } \\
\text { Organizacionais }\end{array}$ & $\begin{array}{c}\text { Transparentes/ } \\
\text { claros }\end{array}$ & $\begin{array}{l}\text { Modelo racional } \\
\text { Palavras chave: verdade, } \\
\text { pensamento, trabalho } \\
\text { Orientado. }\end{array}$ & $\begin{array}{l}\text { Modelo político } \\
\text { Palavras chave: poder, } \\
\text { conflito, força. }\end{array}$ \\
\cline { 2 - 4 } & $\begin{array}{l}\text { Ambíguos/ } \\
\text { não claros }\end{array}$ & $\begin{array}{l}\text { Modelo de sistema social } \\
\text { Palavras chave: confiança, } \\
\text { aprendizagem, colabora- } \\
\text { ção. }\end{array}$ & $\begin{array}{l}\text { Modelo anárquico } \\
\text { Palavras chave: insensa- } \\
\text { tez, aleatoriedade, jogo. }\end{array}$ \\
\hline
\end{tabular}


O modelo político é conceitualmente associado a: poder, conflito e força e, em termos de estruturação organizacional, voltado para objetivos conflituosos, obscuros e não partilhados, apesar de baseado em tecnologias e procedimentos claros. Ellström (2007, p. 452) afirma que, particularmente no caso das escolas, "autores levantaram a hipótese de que as organizações são melhor compreendidas como entidades políticas (MARCH \& SIMON, 1958; CYERT \& MARCH, 1963; PETTYGREW, 1973; PFEFFER, 1981)", ou seja, "como um sistema de interação individual e de subgrupos perseguindo diferentes interesses, demandas e ideologias através do uso do poder e de outros recursos". Pela naturalidade da existência dos conflitos entre indivíduos e grupos lutando pelo poder e pelas tensões e contradições decorrentes da estruturação acadêmica, a imagem da autonomia universitária opera como elemento que fortalece os princípios do modelo político dentro do funcionamento da instituição universidade. No entendimento de Silva (2011, p. 85), a imagem da universidade como lócus político "revela uma estrutura em rede que procura 'conectar' grupos que ora cooperam ora se antagonizam e que, para tal, geram 'centros de decisão' que mobilizam diferentes actores dotados de perícia e recursos com os quais influenciam as decisões". Sobre essa questão, similar linha de pensamento é partilhada por Costa (1996, p. 73), ao entender que a "escola é um sistema político em miniatura cujo funcionamento é análogo ao das situações políticas existentes nos contextos macro-sociais".

O modelo de sistema social é conceitualmente associado: à confiança, aprendizagem e colaboração e, em termos de estruturação organizacional, voltado para tecnologias e procedimentos não claros (ambíguos), com objetivos certos e partilhados. Para Ellström (2007, p. 452), o modelo de sistema social "vê os processos organizacionais como respostas adaptativas espontâneas a problemas internos e externos, ao invés de ações intencionais".

O modelo anárquico é conceitualmente associado: à insensatez, ao jogo e à aleatoriedade e, em termos de estruturação organizacional, voltado para tecnologias e procedimentos não claros (ambíguos), com objetivos conflituosos, obscuros e não partilhados, faltando intencionalidade na ação e consequente desarticulação entre o plano das intenções e o plano da ação. O modelo de anarquia organizada configura uma opção teórica radical e contrária à concepção racional da organização estabelecida pelo modelo burocrático. Atua preenchendo espaço existente na organização, decorrente de falhas e/ou desorganização, bem como nas áreas de rompimento de orientações normativas que se apresentam na realidade do funcionamento organizacional, pela impossibilidade de a racionalidade dominar sempre as condições de ambiguidade estabelecidas na organização. Conforme Silva (2004, p. 73-74), o modelo da anarquia organizada se mostra bastante adequado para explicar "a natureza da dinâmica e das práticas universitárias influenciadas pelo alto grau de autonomia de que gozam quer as estruturas quer os docentes, e da existência de ambiguidades afectas aos objetivos, às relações de poder e às perspectivas futuras que se abrem". Em síntese, o modelo anárquico é um recurso interpretativo quando existe falta de clareza de objetivos e há conflitos, paralelamente com ambiguidades relacionadas a procedimentos e tecnologias organizacionais. Ellström (2007, p. 453) esclarece que o modelo anárquico "é descrito através de três de suas mais bem conhecidas noções como um ponto de partida. Ou seja, as metáforas da 'anarquia organizada' (COHEN et al., 
1972; COHEN \& MARCH, 1974), 'caixote de lixo' (COHEN et al., 1972) e sistemas debilmente articulados (WEICK, 1976), respectivamente".

As conceituações teóricas da anarquia organizada são resultantes de diversos estudos, ainda relativamente recentes, realizados por Cohen, March e Olsen (1972), para caracterizar as organizações com preferências e objetivos inconsistentes e não claramente definidos, cujos procedimentos organizacionais e tecnológicos sejam obscuros ou pouco compreendidos pelos seus membros, e quando as participações dos membros são fluidas. Pelas realidades organizacionais de ambiguidades, entre outras, de preferências e objetivos maldefinidos ou inconsistentes, procedimentos de tentativa e erro, processos não compreendidos pelos seus membros e participação fluida, as instituições educativas podem ser consideradas anarquias organizadas.

Na concepção da metáfora da débil articulação, os elementos de uma organização são, apenas, fracamente conectados uns aos outros, ou seja, constituem-se em um "sistema debilmente articulado". De acordo com Weick (1976), as escolas são "loosely coupled", ou seja, são organizações debilmente acopladas, uma vez que não existem racionalidade e eficiência nos trabalhos de coordenação, bem como as vinculações entre os vários níveis de sua estruturação, rotinas e procedimentos são frágeis, havendo até desarticulação entre os diferentes elementos da estrutura que, apesar de aparentemente integrados, na realidade, funcionam isoladamente, resguardando seus próprios interesses. Sobre a imagem das escolas como sistemas debilmente articulados ("loosely coupled systems"), segundo Lima (1992a, p. 75), é decorrente de que "muitos dos seus elementos são desligados, se encontram relativamente independentes, em termos de intenções e de acções, processos e tecnologias adoptados e resultados obtidos, administradores e professores, professores e professores, professores e alunos, etc".

De forma normativa, a teorização da imagem de acoplamento débil ainda não ocupa lugar superior nas teorias sociais, no entanto as ações organizacionais nem sempre seguem o rito da racionalidade burocrática, tampouco são desenvolvidas de forma conectada e articulada. Muitas relações entre organizações e destas com os ambientes, as relações entre unidades da hierarquia, bem como entre as pessoas, acontecem em contextos "debilmente acoplados". Diversas ações, na prática, são reações ao processo organizacional, configurando uma débil articulação entre as intenções, atividades e ações. No entendimento de Weick (1976, p. 4) devido ao potencial de fraco acoplamento entre as intenções e ações dos membros da organização, não deveria causar estranheza para os administradores o fato de as coisas não acontecerem como deveriam. Nesse contexto, Orton e Weick (1990) entendem que o conceito de sistema de baixo acoplamento é amplamente utilizado e diversamente compreendido e que não tem sido aplicado nas organizações com o poder interpretativo de que a teoria dispõe.

Entre os vários conceitos de referência e imagens das organizações educativas, sobressaem, ainda, as investigações de Tony Bush (1986) cujos resultados foram sistematizados, 
inicialmente, em cinco propostas teóricas ${ }^{1}$ organizacionais de gestão educacional, os modelos: formal, democrático, político, subjetivo e de ambiguidade; aplicáveis, de acordo com as especificidades e tipos das instituições de educação, entendendo-se gestão educacional como campo de estudo e de prática voltada para o desempenho funcional das organizações educativas. Essas cinco perspectivas foram definidas em função da abrangência e tipologia das instituições educacionais, conforme estudos efetivados em escolas primárias, secundárias e faculdades. Segundo Bush (1986), não há dúvida quanto à importância de uma boa gestão para o funcionamento eficaz das escolas e isso é mais significativo para os alunos e estudantes, independentemente do tamanho da instituição de educação.

Os Modelos Formais, que imprimem destaque à estrutura oficial da organização, são concebidos como sistemas hierárquicos em que os chefes buscam a consecução de objetivos e tomam decisões usando, predominantemente, meios racionais. A autoridade dos dirigentes é legitimada por suas colocações formais na estrutura da organização. "As organizações são sistemas hierárquicos em que os gerentes usam meios racionais para perseguir os objetivos acordados" (BUSH, 1986, p. 22).

Os Modelos Democráticos compreendem e integram conceitos que entendem que as políticas e o processo de tomada de decisões nas organizações devem ocorrer pela busca do consenso. O poder é partilhado entre membros da organização. Apresentam características de amplitude normativa, participação, repartição de autoridade e procedimentos de administração colegiada. Considera Bush (1986) que a essência da democracia é a participação na tomada de decisões e o compartilhamento do poder do líder com a equipe.

Os Modelos Políticos assumem o conflito como situação natural e o poder resulta das coligações dominantes, sobrepondo-se ao dos líderes formais. Nesses modelos, as políticas e decisões das organizações resultam de um processo de negociação e disputa, enquanto os objetivos organizacionais são instáveis e ambíguos, e o conflito é visto como uma ocorrência normal.

Os Modelos Subjetivos percebem as organizações como unidades complexas e criações das pessoas que as integram, e também refletem diferentes significados e perspectivas em função da subjetividade e experiências dos seus membros. As organizações são manifestações das percepções individuais derivadas de seus conhecimentos e valores.

Os Modelos de Ambiguidade estão associados a teorias de imprevisibilidade e de objetivos organizacionais não bem definidos, próprio das organizações complexas como escolas. Os modelos ambíguos assumem que a turbulência é um dos fatores dominantes das organizações, que não há clareza e compreensão quanto aos procedimentos e que a participação, na tomada de decisão, é fluida em função dos interesses dos membros. De acordo

1 Em obras posteriores, entre suas propostas de modelos de administração, o autor passou a denominar o "modelo democrático" também como "modelo colegial" e incorporou aos conceitos teóricos da sua tipologia dos modelos de gestão, um sexto, o "modelo cultural", assumindo que as crenças, valores e ideologias são parte central das organizações. 
com Bush (1986), as incertezas advindas do contexto externo aumentam a ambiguidade do processo de tomada de decisão na organização.

Com a compreensão de que os modelos analíticos, por si só, não respondem à complexidade da realidade organizacional, embora sejam capazes de gerar decisivas concepções; e não se excluem mutuamente, ao contrário, às vezes, são complementares e/ou em outras condições passíveis de articulação; Lima (1992a) estruturou um quadro teórico para as organizações educativas, considerando suas híbridas e múltiplas funções e ações, e com respaldo nos modelos organizacionais analíticos/interpretativos, na compreensão de que não se pode "liminarmente fazer corresponder uma determinada concepção a apenas uma imagem ou metáfora" e "menos ainda a um modelo teórico de análise ou a um paradigma" (LIMA, 2011c, p. 21). Nesse contexto, o autor considera o espaço entre as "determinações formais e dos respectivos constrangimentos impostos" da perspectiva burocrática, com outra perspectiva contemplando "a organização e os atores, a ação organizacional", e com base em sólida análise conceitual e empírica, enunciou a proposta teórica de que "a escola não será, exclusivamente, burocrática ou anárquica. Mas não sendo exclusivamente uma coisa ou a outra poderá ser simultaneamente as duas". E este conceito denominou de "modo de funcionamento díptico da escola como organização" (LIMA, 1992a, p. 157).

Assim, é fundamentada uma estruturação teórica de interpretação do funcionamento das organizações educativas com base em modelos e princípios antagônicos, num trânsito entre a escola como organização burocrática, mecanicista, etc. vinculada a conceitos de articulação forte, certeza e ordem; e a escola como organização ambígua, de arena política, sistema debilmente articulado, etc. vinculada a conceitos de articulação fraca, disjunção, subjetividade e desordem. Concretamente, o "modelo díptico" procura organizar, no seu interior, os vários modelos de análise organizacional, imagens e metáforas, entre os dois extremos, ou polos, constituídos pela burocracia racional e a anarquia organizada.

\section{AS INCERTEZAS ORGANIZACIONAIS DOS INSTITUTOS FEDERAIS}

Os Institutos Federais de Educação, Ciência e Tecnologia, criados a partir da transformação/integração dos antigos Centros Federais de Educação Tecnológica e Escolas Técnicas e Agrotécnicas, pela Lei no 11.892, de 29 de dezembro de 2008, definem-se como "instituições de educação superior, básica e profissional, pluricurriculares e multicampi" (BRASIL, 2008), nos termos do artigo 2 o da referida lei; portanto, com características organizacionais formalmente diferenciadas de universidade e dos demais estabelecimentos educacionais existentes no país, inclusive, de outras organizações escolares existentes em países dos

2 De acordo com Lima (2011a, p. 51-52): “Díptico' no sentido em que é dobrado em dois a partir de um eixo constituído pelo plano da ação e por referência ao plano das orientações para a ação, ora exibindo mais um lado, ou face (por exemplo a face burocrática-racional, ou de sistema social), ou outra face (a metaforicamente representada como anárquica, ou ainda aquelas mais associadas aos modelos políticos, ou culturais e subjetivos), ora ainda apresentando as duas faces em simultâneo, ainda que em graus variados de abertura ou de fechamento, ou de presença/ausência face ao observador". 
continentes Americano e Europeu, regiões de forte vinculação acadêmica e de intercâmbio educacional com o Brasil.

Por meio da estrutura multicampi, no cumprimento da função social objeto de suas finalidades e objetivos, sua atuação acadêmica deve garantir, "em cada exercício, o mínimo de $50 \%$ das vagas para cursos técnicos de nível médio, bem como o mínimo de $20 \%$ para cursos de licenciaturas e/ou programas especiais de formação pedagógica, visando à formação de professores para a educação básica e para a educação profissional" (FERNANDES, 2008, p. 62). Por outro lado, como organização educativa, deve ser considerado o Instituto Federal uma "Escola" com múltiplas características e funções a desempenhar, cuja complexidade contempla uma estruturação educacional em vários níveis; uns, próprios de estabelecimentos escolares da educação básica (formação inicial e continuada, ensino médio e ensino técnico); e outros, de universidades (graduação e pós-graduação).

Conforme apresentado na figura 1, a imagem do Instituto Federal assume a forma de uma rede e/ou conjunto de campi com autonomia de administração partilhada com a reitoria, contexto organizacional apoiado em estruturas híbridas, integrado por princípios estratégicos, função social e objetivos institucionais, variáveis de equilíbrio e regulação entre os ambientes internos e externos. Assim, constitui-se numa identidade diferenciada relativamente às outras instituições educacionais do país, com características complexas e de ambiguidade, em virtude da atuação nos diversos níveis da educação nacional com articulação do ensino com a pesquisa e extensão, bem como da organização multicampi que, no entendimento de Pacheco (2012, p. 11), significa colocar os Institutos Federais "em contato direto com as demandas locais, sejam elas de ordem econômica ou social. A afirmação dessa rede nos espaços territoriais permitirá que o conhecimento nela desenvolvido se volte às reais necessidades que emergem desses contextos".

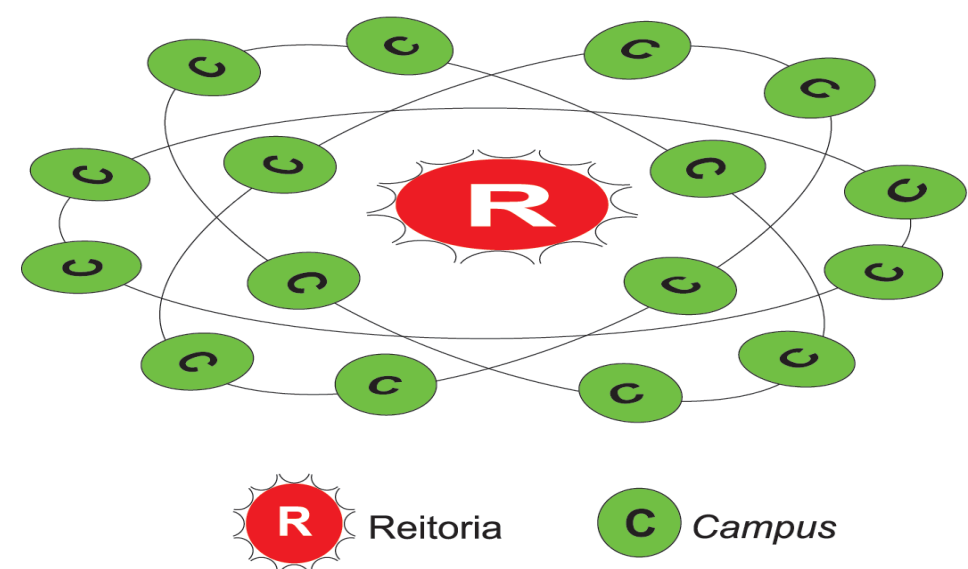

Figura 1: Representação gráfica da configuração estrutural do Instituto Federal. Elaboração própria.

Concernente à hierarquização estabelecida nos termos da lei, a administração dos Institutos Federais terá como órgãos superiores o Colégio de Dirigentes, de caráter consultivo, e o Conselho Superior, de caráter deliberativo e consultivo; e como órgão executivo a reitoria, 
composta por 1 (um) Reitor e 5 (cinco) Pró-Reitores, conforme demonstrado na figura 2. A estruturação da reitoria organizada com base em pró-reitorias de áreas e dimensões estratégicas, entre outros aspectos, amplia o fluxo hierárquico de verticalização entre reitor e direções dos campi, incorporando decisões transversais, emanadas dessas dimensões para áreas afins nos campi, transformando o processo num sistema de interação matricial.

ORGANOGRAMA BÁSICO DE UM INSTITUTO FEDERAL (LEI N 11.892/2008).

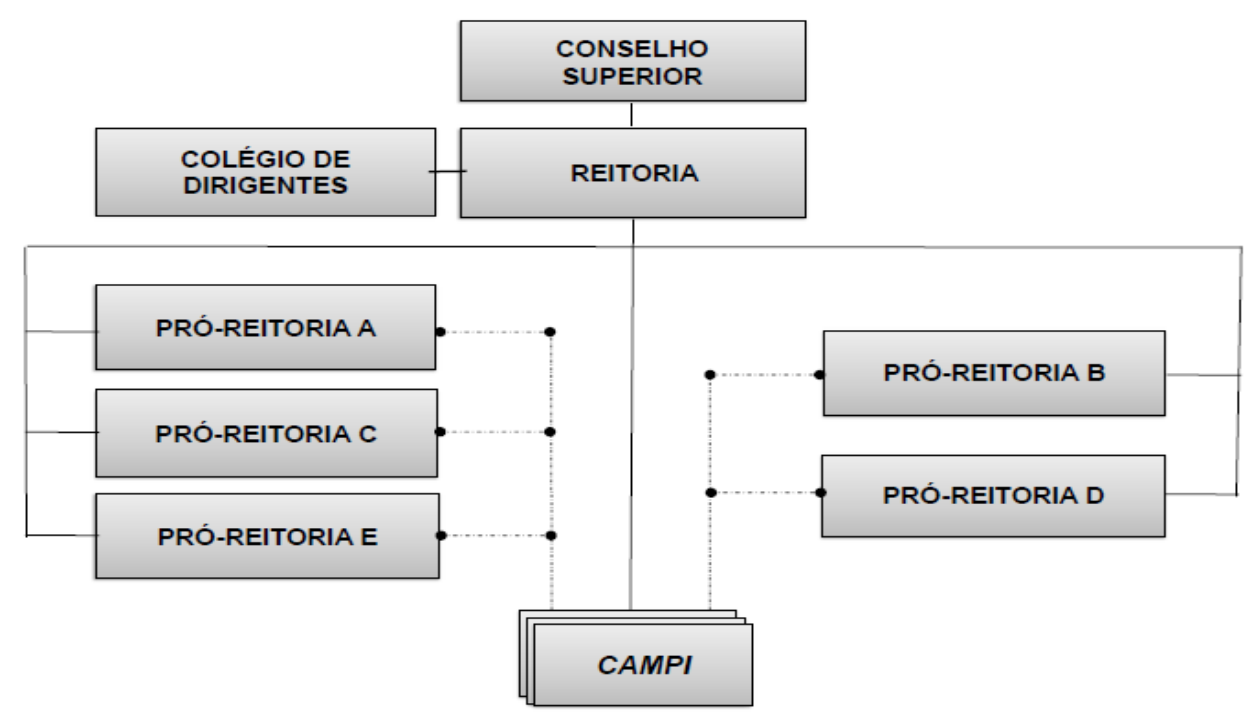

Figura 2: Representação esquemática do Organograma do Instituto Federal, nos termos da Lei no 11.892/2008. Elaboração própria.

O contexto de variáveis multifacetadas recomenda algumas apreciações acerca das representações teóricas do IF como: "instituto racional/burocrático", "instituto anárquico" e "instituto debilmente articulado", em conexão com os princípios do "modo de funcionamento díptico da escola como organização".

\section{O "INSTITUTO RACIONAL/BUROCRÁTICO"}

É coerente a perspectiva da associação da organização Instituto Federal (IF) a imagens múltiplas (atuações multicampi e multinível, além de circunstâncias multifacetadas e híbridas), tendo em vista "estar a assumir simultaneamente múltiplos e diversos selves" (MAGALHÃES, 2004), situação favorável a incertezas e não efetividade de ações. Contudo, a confrontação da estruturação dos Institutos Federais com as características das organizações burocráticas3 permite um delineamento de imagem organizacional permeada de muitas racionalidades, próprias dos sistemas burocráticos (WEBER, 1978), tendo em vista a vocação de centralidade

3 De acordo com Max Weber (1997, p. 46): “Naturalmente há muitas diferenças entre as várias espécies de burocracia: entre a administração militar e civil, entre Estado e partido, entre comunidade, igreja, banco, cartel, cooperativa de produtores, fábrica e grupo de interesse (como associações de empregadores ou a Liga dos Agricultores). 
administrativa pela existência de princípios e características de legalidade, com a estrita submissão normativa à Lei no 11.892, de 29 de dezembro de 2008, instrumento de concentração de objetivos estratégicos e da política organizacional, numa concepção de ajustamentos dos meios para a obtenção dos fins, além de perspectivas de previsibilidade máxima, de racionalização de recursos e consecução de ampla eficiência. "A administração burocrática exerce a dominação de forma racional, subsidiada por parâmetros rigorosamente formal e legal" (TAVARES, AZEVEDO e MORAIS, 2014, p. 161).

A Reitoria absorve e representa o poder formal-legal centralizador de regulação (leis, decretos, portarias, instruções normativas, acórdãos, resoluções, pareceres, notas técnicas, etc) do "Estado", como órgão executivo da autarquia detentora de autonomia didático-pedagógica, patrimonial, financeira, administrativa, disciplinar e de gestão de pessoas. Especialmente, no tocante à área de gestão de pessoas, considerada uma questão diferencial nas organizações, apresenta-se no IF como desafio quanto à concepção e implementação de um modelo administrativo que contemple os procedimentos próprios da racionalidade, determinados "por 'cipoal' de normas e instruções regulamentadoras advindas de órgãos superiores executivos e de controle" (FERNANDES, 2015, p. 262), bem como as especificidades de quadros de pessoal individualizados por unidade administrativa (reitoria e campi) e as expectativas organizacionais dos serviços e atores.

No entendimento de Bresser-Pereira (2004, p. 14): "As burocracias têm sua fonte de legitimidade no poder racional-legal, e não no poder patriarcal, patrimonial ou caristmático. Em seu tipo ideal, puro, as organizações são sistemas sociais racionais". Extensivamente, a administração do IF é pautada por um amplo arcabouço burocrático de normas escritas, compreendendo: Estatuto, Regimento Geral, Regimento do Conselho Superior (Consup), do Colégio de Dirigentes (Codir) e demais colegiados criados no âmbito da reitoria e dos campi, que estabelecem, detalhadamente, competências e vinculações de subordinação, além da sistematização da execução de atividades e funcionamento de órgãos e unidades. No entendimento de Peter Berger (1983, p. 44), a "lógica do comportamento administrativo é determinada por processos burocráticos", enfatizando ainda o autor que o funcionamento da máquina burocrática é sempre muito parecido "em toda parte, quer na Igreja Metodista, numa repartição do governo federal, na General Motors ou no Sindicato dos Trabalhadores da Indústria" (BERGER, 1983, p. 44-45). Por outro lado, em contraponto, entende Costa (2004, p. 86) que o mesmo poder político-administrativo "que legisla no sentido da centralidade do projecto educativo na gestão das escolas cria também condições legais para que tal não se verifique - ora legislando mesmo no sentido da sua inoperância, ora mantendo em vigor legislação inconsequente e contraditória".

Do conjunto, emerge um sistema racional de divisão de trabalho de feição hierárquica, no entanto, apesar da conformidade em vários aspectos, constata-se que o modelo racional/burocrático não consegue contemplar explicações acerca de diversos fatores organizacionais encontrados na dinâmica de uma unidade escolar, cuja gestão demanda níveis de descentralização e delegação de competências, especialmente constituído por um ordenamento matricial híbrido com articulações frágeis, inclusive compreendendo poder fundamentado em 
conhecimento especializado nos campi, além de ampla conjuntura de poder não-formal, concorrendo esses elementos e condições para situações de indefinições e desorganizações.

\section{O “INSTITUTO ANÁRQUICO”}

Efetivamente, ao observar o Instituto Federal numa perspectiva das anarquias organizadas4, identificam-se várias incertezas e ambiguidades dessa organização, condições peculiares à imagem do modelo anárquico. Segundo a concepção de Cohen e March (1974), as organizações, muitas vezes, fazem escolhas sem objetivos claros. Muitas dessas inconsistências são originárias da autonomia acadêmica exercida pelo poder dos peritos, das estruturas informais instaladas pelos atores organizacionais ou decorrentes de conflitos, percepções e ações diversas casualmente vivenciadas e sem claras conexões. Algumas, porém, têm procedência a partir do próprio marco legal do sistema burocrático de sustentação da organização.

Em princípio, as características da macroestrutura organizacional legalmente definida, de autonomia administrativa e financeira dos campi, relativamente ao poder central (reitoria), conduzem, na ação, a ambiguidades nos processos decisórios em decorrência de objetivos não partilhados e inconsistentes, especialmente na ação de articulação da reitoria com os campi, os quais, muitas vezes, podem ser levados por interesses divergentes entre o plano das intenções e o plano da ação.

No Instituto, num contexto de "uma organização composta de organizações" (FERNANDES, 2008), muitas vezes, os campi podem atuar remodelando os objetivos firmados a partir da reitoria, materializando-se, assim, a falta de intencionalidade única da ação organizacional. É incerta a forma de apropriação das decisões dos órgãos colegiados superiores junto à comunidade, bem como frágeis os sistemas de informações e de controle e acompanhamento entre colegiados e os campi, muito dependentes de ações assumidas ou não pelos conselheiros junto às suas respectivas bases representativas. Na prática, essa organização multicampi provoca percepções e ações inerentes à natureza anárquica de uma estrutura dispersa, de ambiguidade da missão educativa e prioridades do Instituto Federal, ultrapassando as contradições da organização escola que levam a "infidelidades normativas", na concepção de Lima (2011a, p. 115), "de margens de autonomia relativa, o que Ihes permite umas vezes retirar benefícios da centralização e, outras vezes colher vantagens de iniciativas que a afrontam", ratificando a perspectiva de que muitos "esforços para determinar instruções normativas e

Lima (2011a, p. 33) considera o “princípio de que qualquer organização, e especialmente as organizações educativas e outras organizações públicas, pode ser entendida, pelo menos parcialmente, como uma anarquia organizada, ou seja, como uma organização em que poderemos encontrar três características gerais, ou três tipos de ambiguidade:

1) objetivos e preferências inconsistentes e insuficientemente definidos e uma intencionalidade organizacional problemática;

2) processos e tecnologias pouco claros e pouco compreendidos pelos membros da organização;

3) participação fluida, do tipo part-time". 
metas na universidade tendem a produzir objetivos que são sem sentido ou duvidosos" (COHEN; MARCH, 1974, p. 195-196).

A função social dos campi, articulada ao aspecto de territorialidade, encontra, no modelo da anarquia organizada, condições de flexibilidade favoráveis à adequação do Instituto Federal aos fatores ambientais locais, preservando, contudo, as consequências dessas alterações para o todo da organização. Concomitantemente, a estrutura de tecnologia matricial produz indefinições quanto às linhas de responsabilidade e/ou autoridade, o que conduz a ambiguidades na ação da política institucional pela oportunidade de atuação de órgãos sistêmicos na ação dos campi, causando fragilidades ao processo. Verificam-se, assim, tecnologias frágeis, desconexões e acoplamentos fluídos na dinâmica da organização educativa Instituto Federal, numa condição de mediação de forças entre a burocracia e a anarquia organizada, além de outras imagens.

\section{O “INSTITUTO DEBILMENTE ARTICULADO"}

A concepção estrutural do Instituto Federal se assemelha a uma "federação interdependente de campi" (FERNANDES, 2015), relativamente autônomos quanto à conformidade e atuação regional, vinculados à realidade social dos respectivos territórios, integrados por acoplamentos frouxos com a reitoria (sede). Essa imagem é coerente com a compreensão exposta por Weick $(1976$, p. 1) de que em contraste com a imagem predominante de que elementos em organizações são acoplados através de ligações densas, apertadas, na prática, apenas esses "elementos são muitas vezes amarrados juntos com frequência e vagamente".

Por outro lado, essa condição de ambiguidade e representativa de débil articulação é confrontada com: Projeto Político-Pedagógico (PPP), Plano de Desenvolvimento Institucional (PDI) e quadro de pessoal, unificados, além dos marcos legais da estruturação burocrática de constituição e funcionamento da organização. Isso vem caracterizar a existência de uma situação de planejamento, de consensos na busca por objetivos gerais, ou seja, que, de fato, a estrutura e ações organizacionais, mesmo se apresentando com debilidade, estejam submetidas a articulações de caráter burocrático.

$\mathrm{Na}$ área de gestão de pessoas, por exemplo, o domínio de articulações débeis não se coaduna com uma ação centralista própria do rigor normativo burocrático, o que exige mudança comportamental e novos padrões de gestão pública, direcionando a política de pessoal no Instituto Federal no sentido de uma nova cultura e identidade, "uma capacidade própria de aprendizagem" (CANAVARRO, 2000, p. 91). Concretamente se impõe a valorização dos interesses dos atores em participar das propostas e decisões, integrando conceituações da cultura organizacional constituída e sustentada nas políticas governamentais, caracterizadas muitas vezes como sistemas impositivos e de controle da ordem, a princípios paralelamente voltados para a proteção das pessoas contra a possibilidade da prática de abusos e injustiças aos seus regulares direitos.

No caso dos projetos educativos, a questão da imposição normativa - por meio da aplicação obrigatória e generalizada a todas as escolas e centralmente decretados - em 
consonância com o posicionamento de Costa (2003, p. 1329), "parece assumir mesmo uma certa contradição com a própria noção de projecto, já que, nesse caso, perder-se-ia aquilo que lhe é mais intrínseco: a iniciativa, a intenção, a adesão natural e voluntária, o relevo dado ao actor como autor do seu próprio projecto". Entre reitoria e os campi, afigura-se uma dinâmica de equilíbrio controverso, originando consequentes articulações débeis entre a autonomia e o controle, e interesses e coordenação, num contexto onde "o local e a região são olhados como o espaço de ação e de desenvolvimento, em torno do qual os consensos e mobilizações têm lugar ou são obstruídos" (ANTUNES, 2013, p. 104).

A vocação burocrática das regulações regimentais, dos atos normativos e diretivas dos órgãos colegiados superiores e reitoria, tem sua força enfraquecida por articulações e conexões que se concretizam frágeis junto aos campi, pelo confronto com as realidades e interesses das comunidades locais, também pela concorrência entre o poder da administração e o poder dos profissionais, além de redes de estruturas formais e as regras e mecanismos informais. Teoricamente, quanto mais poder for delegado aos campi, maior será a independência deles para com a reitoria. Essa situação conceitual é própria para o desenvolvimento de sistema de controle de desempenhos que, nos sistemas de ensino, conforme o entendimento de Magalhães (2001, p. 138), parece ter "caráter paradoxal, ambíguo", já que dá à autonomia conferida às instituições escolares "o caráter híbrido, isto é, de mistura de regulação estatal e de lógica de autoregulação".

Apesar de a racionalidade ainda continuar sendo uma das características significativas das unidades educacionais, entende Silva (2004, p. 84) que "isso não afectará a flexibilidade organizacional necessária à adaptação dessas organizações aos novos contextos sociais" de superação de oposições teóricas e dicotomias analíticas fracionadas, associadas a uma perspectiva de complementaridade de imagens próprias das organizações educativas, o que recomenda as conceituações da teoria do "modo de funcionamento díptico da escola como organização" para a compreensão das tensões e procedimentos resultantes da dinâmica complexa do Instituto Federal.

\section{O INSTITUTO SOB A PERSPECTIVA DO “MODO DE FUNCIONAMENTO DÍPTICO”}

O contexto do Instituto Federal (IF) como uma organização complexa, de estruturação híbrida $^{5}$ e de especificidades peculiares, em função da concomitância de componentes vinculados à colegialidade, à burocracia, à autonomia dos professores e às ambiguidades, em que se embasa e se desenvolve a ação organizacional e são tomadas as decisões, conduz a circunstâncias que extrapolam as características definidas por Mintzberg (1995) como

Segundo Wood Jr (2010, p. 242-243), a "análise da literatura existente permite deduzir que, nas organizações, o processo de hibridização e a condição híbrida contém um forte componente de indeterminação, pois pode desestabilizar os referenciais existentes e turvar as distinções entre cultura local e cultura corporativa. Em empresas transnacionais, por exemplo, os esforços corporativos para impor valores e práticas podem esbarrar em respostas defensivas de executivos locais, que mesclam tais valores e práticas com seus próprios valores e práticas, gerando híbridos. Além disso, diferentes contextos institucionais e culturais - países ou regiões - podem gerar diferentes respostas e diferentes híbridos". 
"burocracia profissional" para as universidades, relacionadas a uma estrutura democrática em que profissionais controlam o trabalho e decisões administrativas e descentralizadas nas dimensões vertical e horizontal, além da convivência de hierarquias administrativas paralelas, uma na direção ascendente, mais democrática, e outra, na direção descendente, de característica mecanicista, de controle das funções de apoio.

Os conceitos teóricos de múltipla abordagem das organizações educativas definidos por Lima (1992a) podem capturar um espaço representativo da realidade estrutural do IF, como reflexo das ações e situações burocráticas e/ou anárquicas, isoladamente ou, às vezes, de forma simultânea, integrando-se, nesse contexto, o recurso das imagens da metáfora dos sistemas debilmente articulados, cuja natureza contempla área de interligação frouxa entre os padrões burocráticos e as ambiguidades da anarquia organizada. Na compreensão do autor, o estudo sociológico das organizações "concentra-se predominantemente no plano da acção organizacional e, no que ao plano das orientações diz respeito, focaliza sobretudo outro tipo de estruturas e de regras, menos visíveis" (LIMA, 1992a, p. 160).

Assim, é provável que se alcancem as dimensões da complexidade organizacional definidas pelas trilhas e marcas das formalidades de procedimentos da estrutura burocrática, e dos aspectos informais não explícitos, caracterizados por ambiguidades, ações não claras, incertezas e situações de débeis articulações. Na concepção de Antunes (2013, p. 106), a "ambiguidade e a ambivalência dos processos que constroem esses arranjos institucionais insinuam-se no discurso em que transparece a tentativa de uma débil articulação de lógicas em tensão".

Observando o Instituto Federal sob as lentes "do modo de funcionamento díptico da escola", no percurso continuum da anarquia organizada à burocracia racional, desponta a perspectiva de identificação de diagrama de área oculta que se delineia como imagem projetada (figura 3) da dinâmica da ação, pelos vestígios derivados dos diversos modelos de análise e imagens organizacionais. A interpretação gráfica, assume, metaforicamente, uma concepção de configuração descrita de forma implícita por Lima (1992a), ao estabelecer que a escola não será, "exclusivamente, burocrática ou anárquica. Mas não sendo exclusivamente uma coisa ou a outra poderá ser simultaneamente as duas". 


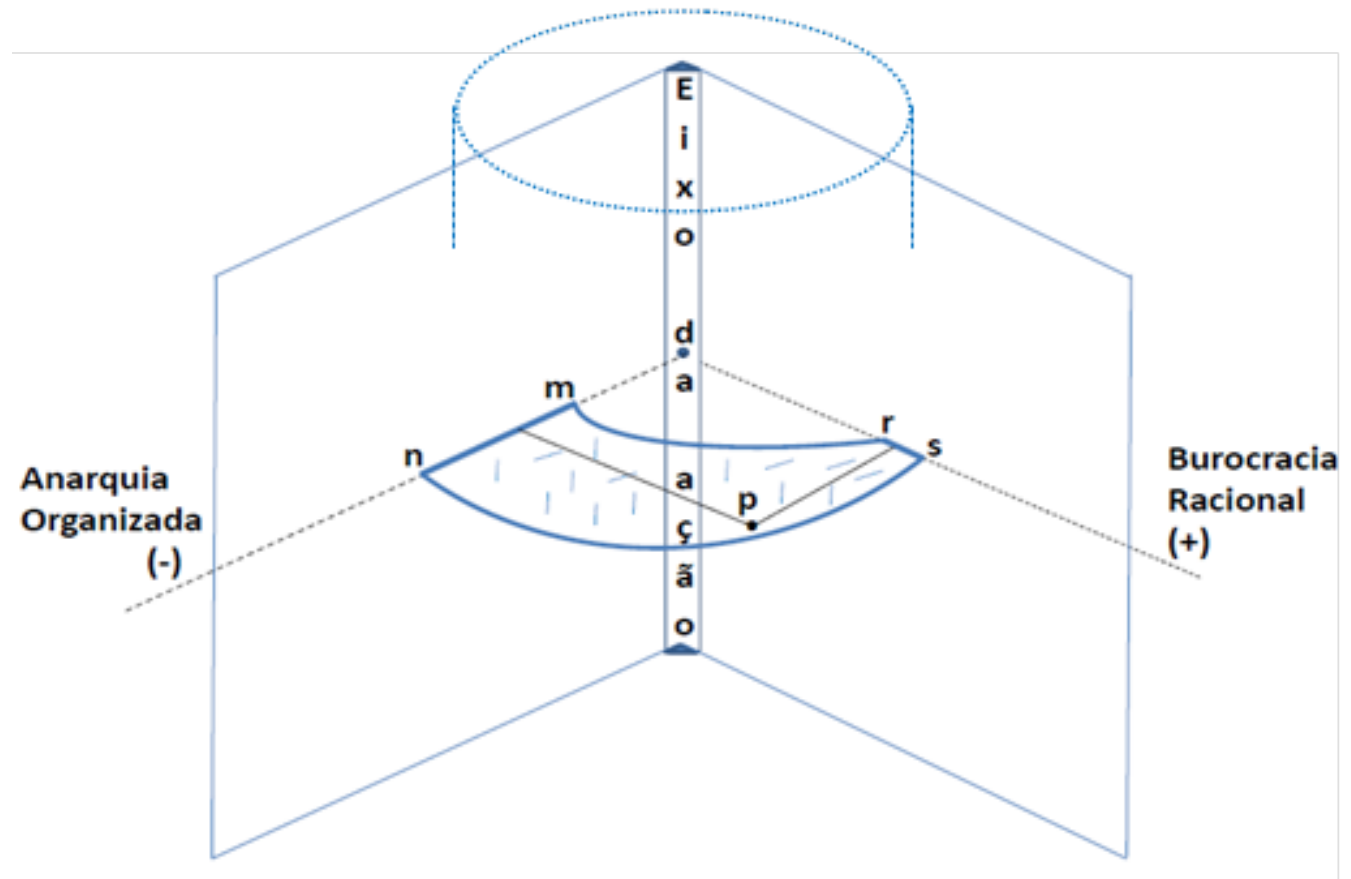

Figura 3: Imagem de área genérica emergente da ação organizacional do Instituto Federal, observada esta sob as lentes da teoria do "díptico". Elaboração própria, por adaptação. Fonte: “Modo de funcionamento díptico da escola como organização" (LIMA, 2011a, p. 52).

Recorrendo à perspectiva de que a "sociologia não é uma ação, e sim uma tentativa de compreensão" (BERGER, 1983, p. 13), é possível vislumbrar que a área revelada, na figura 3, e delimitada pelos vértices $m-n-s-r$, constituída por " $z$ " pontos (p), é, a princípio, elementos de projeções das realidades de fracas articulações ou acoplamentos frouxos, caracterizando pontes de ligação e de flexibilidade que se configuram entre os modelos burocráticos e da anarquia organizada no desenvolvimento da ação organizacional. Esse ambiente simboliza, também, o lugar da coexistência da ordem burocrática cumulativamente com a ordem anárquica.

De forma abstrata e interpretativa, não parece impróprio imaginar, compreensivamente, a incorporação espacial na área desenhada pelos vestígios das ações vivenciadas na organização, de aspectos de aprendizagem e colaboração do modelo de sistema social, e de conflito e poder do modelo político, contemplando, assim, a teoria conceitual das 4 (quatro) faces da escola como organização definida por Ellström (2007).

Retornando aos aspectos e limites constantes do diagrama da figura 4, numa condição teórica "pura" de anarquia organizada, emerge da ação organizacional a imagem do segmento de reta $\mathrm{m}-\mathrm{n}$, com o posicionamento e tamanho variável, projetados sobre o respectivo eixo. Perspectiva idêntica vivencia-se no caso da situação "ideal" de burocracia racional, para o segmento de reta $r$-s.

Com respaldo nesses focos de visibilidade, é identificável no IF, por um lado, uma perspectiva atrelada a uma estabilidade com base em normalizações e hierarquia de autoridade claramente definida, associada, racionalmente, à consecução de objetivos predeterminados. Noutros aspectos, encontram-se as desconexões de ambiguidades e das relações debilmente articuladas, advindas da rede de estruturação de concepção matricial e da arquitetura de 
autonomia entre reitoria e os campi6, que viabilizam amplas condições para o surgimento de pleitos de estratégias variadas, conforme o interesse de atores e segmentos ou representações da comunidade. Isso conduz, em muitos casos, ao estabelecimento de conflitos, cujos encaminhamentos de superação requerem negociações e/ou utilização de recurso à legislação, para a composição das respostas. Na compreensão de Silva (2004, p. 105), essas questões ocorrem de forma tão complexa "que é difícil distinguir se o que acontece está dentro dos parâmetros de uma comunidade colegial munida de autonomia ou se corresponde aos parâmetros de uma burocracia típica". A esse propósito, enfatiza o autor que, no âmbito da organização universitária, não se pode estabelecer uma "separação nítida entre as estruturas e sistemas burocráticos e as formas de organização políticas ou anárquicas, até porque as mesmas estruturas realizam, simultânea ou desfasadamente, quer umas quer as outras funções" (SILVA, 2004, p. 105).

\section{REFERÊNCIAS CONCLUSIVAS}

Num contexto efetivo, a organização Instituto Federal (IF) abrange múltiplas dimensões e imagens, e estruturalmente, enquadra-se e pode ser igualado, em termos de parâmetros, à configuração de uma Estrutura Divisionalizada (MINTZBERG, 1995). Compõe-se da sede (reitoria), coordenando um conjunto de organizações educativas semiautônomas (campi), cada uma com estrutura administrativa própria, responsável pela implementação das ações de ensino, pesquisa e extensão, de atendimento à sociedade. A reitoria e órgãos superiores se incumbem das funções estratégicas, da alocação geral de recursos, da definição de políticas e supervisão direta do desempenho dos campi.

A estrutura divisionalizada se delinea, matricialmente, de forma vertical, horizontal e transversalmente, integrando unidades dos organogramas da reitoria e dos campi, bem como associada às medidas de descentralização e autonomia partilhada, especialmente, entre o Reitor e os Diretores-Gerais dos Campi, estabelecendo-se, assim, o que se percebe como uma "convivência relativa de poder" (FERNANDES, 2015, p. 458).

Simultaneamente burocrática e anárquica, sob tensões de uma estruturação matricial com ancoragem entre centralização e descentralização, a ação organizacional do IF demanda articulações fracas para funcionar adequadamente, com certo duvidoso equilíbrio, em função dos níveis de independência dos atores. O campo de tensões e de relações de forças que se cria entre administração central, a gestão dos campi e as comunidades escolares, na maioria do tempo de estabilidade, advinda de consensos e acomodações, oportunizam, também, instabilidades e conflitos, em muitos casos, neutralizados pelas partes e pessoas a agirem sob uma certa coerência de confiança (ORTON e WEICK, 1990), situações que umas atribuem às outras partes, a pressuposição de ação com honestidade e transparência.

6 Em consonância com estudos sobre a configuração organizacional de instituições universitárias, composta por estruturas individualizadas, a compreensão de Silva (2004, p. 106) é de que "estas estruturas, apesar de autónomas, estão levemente articuladas na medida em que, tendo de realizar cada uma delas as suas próprias funções e atribuições, fazem-no dentro dos parâmetros e 'regras de jogo' estabelecidas". 
Na compreensão de Weick (1976), os acoplamentos fracos e/ou as débeis articulações são evidentes quando elementos do funcionamento afetam, entre outras formas, uns aos outros: ocasionalmente, indiretamente e eventualmente, realidades inerentes a ações e padrões da autonomia multicampi e de ofertas educacionais multiníveis, consonantes com os tipos regulares de "acoplamentos frouxos", delimitados por Orton e Weick (1990), estabelecidos entre: indivíduos, níveis hierárquicos, subunidades, organizações e ambientes, e/ou intenções e ações.

Em síntese, de maneira efetiva, a estrutura de autonomia relativa multicampi e de oferta de múltiplos níveis educacionais gera, na ação do Instituto Federal, um espaço de articulações débeis entre as faces da anarquia organizada e da burocracia racional, sendo essas faces, contudo, os marcos de sustentação de um certo acoplamento, ainda que tenso e, frequentemente, contraditório. Essa característica deve ser entendida como fundamento interdependente de uma dinâmica organizacional escolar em rede.

\section{REFERÊNCIAS}

ANTUNES, Fátima. Reforma do Estado e políticas públicas: a governação em ação (Notas de um estudo no campo da Educação e Formação de Adultos em Portugal). In PERONI, Vera Maria Vidal (org). Redefinições das fronteiras entre o público e o privado: implicações para a democratização da educação. Brasília: Liber Livro, 2013, p. 82-119.

BERGER, Peter L. Perspectivas sociológicas: uma visão humanística; tradução de Donaldson M. Garschagen. 6a ed. Petrópolis: Vozes, 1983.

BRASIL. Lei no 11.892, de 29 de dezembro de 2008. Disponível em: https://www.planalto.gov.br/ccivil_03/_ato2007-2010/2008/lei/I11892.htm. Acesso em: 29 abr.2016.

BRESSER-PEREIRA, L. C. A Organização Burocrática. In MOTTA, Fernando C. Prestes e BRESSERPEREIRA, L. C. Introdução à Organização Burocrática. São Paulo: Thomson, 2004, p. 1-39.

BUSH, Tony. Theories of educational management. London: Paul Chapman, 1986.

CANAVARRO, José Manuel. Teorias e Paradigmas Organizacionais. Coimbra: Quarteto, 2000.

COHEN, Michael D. e MARCH, James G. Leadership and Ambiguity: the American College President. New York: McGraw-Hill, 1974.

COHEN, Michael D.; MARCH, James G. e OLSEN, Johan P. A Garbage Can Model of Organizational Choice. Revista Administrative Science Quarterly, Michigan, ISSN: 0001-8392, v. 17, n.1, p. 1-25, 1972.

COSTA, Jorge A. Imagens Organizacionais da Escola. Porto: Edições ASA, 1996.

COSTA, Jorge A. Projectos educativos das escolas: um contributo para a sua (des)construção. Revista Educação \& Sociedade, Campinas, ISSN: 0101-7330, v. 24, n. 85, p. 1319-1340, 2003. 
COSTA, Jorge A. Construção de projectos educativos nas escolas: traços de um percurso debilmente articulado. Revista Portuguesa de Educação, Braga, ISSN: 0871-9187, v. 17, n. 2, p. 85-114, 2004.

ELLSTRÖM, Per-Erik. Quatro faces das organizações educacionais, tradução de Ângelo Ricardo de Souza e Taís Moura Tavares. Revista Brasileira de Política e Administração da Educação, Porto Alegre, ISSN: 1678-166X, v. 23, n.3, p. 449-491, 2007.

FERNANDES, Francisco C. M. Novo design para a Rede Federal de Educação Tecnológica. Revista Holos, Natal, ISSN 1807-1600, v. 3, p. 56-66, 2008.

FERNANDES, Francisco C.M. Racionalidades e Ambiguidades da Organização Instituto Federal: o caso do Rio Grande do Norte. Braga: Universidade do Minho - Instituto de Educação, 2015.

LIMA, Licínio C. A Escola como Organização e a Participação na Organização Escolar. Braga: Universidade do Minho - Instituto de Educação, 1992a.

LIMA, Licínio C. Organizações Educativas e Administração Educacional em Editorial. Revista Portuguesa de Educação, Braga, ISSN: 0871-9187, v. 5, n. 3, p. 1-8, 1992 b.

LIMA, Licínio C. A escola como Organização Educativa: uma abordagem sociológica - 4. ed. - São Paulo: Cortez, 2011a.

LIMA, Licínio C. Administração Escolar: Estudos. Porto: Porto Editora, 2011b.

LIMA, Licínio C. Concepções de escola: para uma hermenêutica organizacional. In LIMA, Licínio C. (org). Perspectivas de análise organizacional das escolas. Vila Nova de Gaia: Fundação Manuel Leão, 2011c, p. 15-57.

MAGALHÃES, António M. A transformação do modo de regulação estatal e os sistemas de ensino: a autonomia como instrumento. Revista Crítica de Ciências Sociais, Coimbra, ISSN: 21827435, n. 59, p. 125-143, 2001.

MAGALHÃES, António M. A identidade do ensino superior: política, conhecimento e educação numa época de transição. Lisboa: Fundação Calouste Gulbenkian, 2004.

MINTZBERG, Henry. Estrutura e Dinâmica das Organizações; tradução de Amélia Salavista Brooker - revisão técnica de António Caetano. Lisboa: Publicações Dom Quixote, 1995.

ORTON, J. Douglas e WEICK, Karl E. (1990). Loosely Coupled Systems: A Reconceptualization. Revista Academy of Management Review, Washington D.C, ISSN: 0363-7425, v. 15, n.2, p. 203223, 1990.

PACHECO, Eliezer. Institutos Federais: um futuro em aberto. In SOUZA, Eda C. Lucas e CASTIONI, Remi (orgs). Institutos Federais: os desafios da institucionalização. Brasília: UNB, 2012, p. 7-11. 
SANDER, Benno. Administração da educação no Brasil: é hora da relevância. Educação Brasileira Revista do Conselho de Reitores das Universidades Brasileiras, Brasília, INSS: ISSN 0102-3209, ano IV, n.9, p. 8-27, 1982.

SANDER, Benno. Administração da Educação no Brasil: genealogia do conhecimento. Brasília: Liber Livro, 2007.

SILVA, Eugénio A. O Burocrático e o Político na Administração Universitária. Continuidades e Rupturas na Gestão dos Recursos Humanos Docentes na Universidade Agostinho Neto (Angola). Braga: Universidade do Minho - Instituto de Educação e Psicologia, 2004.

SILVA, Eugénio A. Um olhar organizacional à luz das perspectivas de análise burocrática e política. In LIMA, Licínio C. (org). Perspectivas de análise organizacional das escolas. Vila Nova de Gaia: Fundação Manuel Leão, 2011, p. 59-108.

TAVARES, A. M. B. N.; AZEVEDO, M.A. e MORAIS, P. S., A administração burocrática e sua repercussão na gestão escolar. Revista Holos, Natal, ISSN 1807-1600, ano 30, v. 2, p. 154-162, 2014.

WEBER, Max. Os Fundamentos da Organização Burocrática: uma construção do tipo ideal. In CAMPOS, Edmundo (organização e tradução). Sociologia da Burocracia, 4. ed. - Rio de Janeiro: Zahar, 1978, p. 15-28.

WEBER, Max. Os Economistas - Textos Selecionados; traduções de Maurício Tragtenberg, Waltensir Dutra, Calógeras A. Pajuaba, M. Irene de Q. F. Szmrecsányi e Tamás J. M. K. Szmrecsányi - São Paulo: Nova Cultural, 1997.

WEICK, Karl E. Educational Organizations as Loosely Coupled Systems. Revista Administrative Science Quarterly, Michigan, ISSN: 0001-8392, v. 21, n.1, p. 1-19, 1976.

WOOD JR, Thomaz. Organizações híbridas. Revista de Administração de Empresas, São Paulo, ISSN: 0034-7590, v. 50, n. 2, p. 241-247, 2010. 